\title{
Association of human leukocyte antigen groups with oral mucositis in patients undergoing bone marrow transplantation
}

\section{Ayse Nur Tufan}

Haseki Training and Research Hospital: department of rheumatology

\section{Fatma Savran Oguz}

Istanbul University Istanbul School Of Medicine Department Of Medicla Biology

Fatih Tufan ( $\square$ fatihtufan@gmail.com )

Private Practice https://orcid.org/0000-0003-3245-1618

\section{Cigdem Kekik}

Istanbul University Istanbul School Of Medicine Department Of Medicla Biology

\section{Fatma Bilgin Tarakci}

Istanbul University Istanbul School Of Medicine Department Of Medicla Biology

\section{Deniz Sargin}

Istanbul University Istanbul School Of Medicine Department Of Medicla Biology

\section{Sevgi Kalayoglu Besisik}

Istanbul University Istanbul School Of Medicine Department Of Medicla Biology

\section{Research}

Keywords: Stem Cell Transplantation, Conditioning Regimen, Transplant Related Toxicity

Posted Date: October 21st, 2020

DOl: https://doi.org/10.21203/rs.3.rs-95021/v1

License: (c) (1) This work is licensed under a Creative Commons Attribution 4.0 International License.

Read Full License

Version of Record: A version of this preprint was published at Leukemia Research on October 1st, 2019. See the published version at https://doi.org/10.1016/S0145-2126(19)30329-7. 


\section{Abstract}

Background: Oral mucositis (OM) after hematopoetic stem cell transplantation (HSCT) may lead to toxicity that impair quality of life. Associations between some diseases and human leukocyte antigen (HLA) groups have been long recognized. A genetic contribution as the association of HLA groups with OM after HSCT, has not been reported to date. We aimed to assess whether an association of HLA phenotype and OM after allogeneic HSCT exists.

Methods: This was a prospective observational study in which OM was assessed with clinical questioning and examination. Association of OM with gender, age, HLA phenotypes, diagnosis, conditioning regimen, stem cell source, engraftment times, and complications was investigated.

Results: 45 patients were enrolled. All the patients with HLA-B44 phenotype developed mild OM, while all patients with HLA-DR15 phenotype developed severe OM. HLA-A23, HLA-B21, HLA-B44, HLA-DR15, and HLA-DR11 were associated with shorter OM duration. HLA-A26 and HLA-B52 were associated with longer $\mathrm{OM}$ duration. Myeloablative conditioning regimen and longer duration of neutropenia were associated with longer OM duration. Regression analysis revealed HLA-B44 and HLA-DR11 as independent factors associated with milder OM.

Conclusion: We identified that some HLA alleles correlated with OM severity and duration. These findings may facilitate predicting risk of morbidity and may provide incorporation of individualized preventive and treatment approaches.

\section{Introduction}

Oral mucositis (OM) is a frequent early-term complication of hematopoetic stem cell transplantation (HSCT) which influences life quality and is associated with increased morbidity $(1,2)$. Beyond individual oral care, underlying disease, type and number of prior chemo and/-or radiotherapy, and conditioning regimen (CR), genetic factors may also have a role in OM development $(1,3-5)$. The primary use for human leukocyte antigen (HLA) testing is to match organ and tissue transplant recipients with compatible donors (6). On the other hand, some HLA-phenotypes may promote some diseases like autoimmune diseases or cancer. Behçet's disease, gluten enteropathy, and inflammatory bowel diseases (IBSs) are disorders with mucosa inflammation and have association with certain HLA phenotypes (7-9). The development of mucosa inflammation in HSCT is multi-factorial, primarily seems to be related to CR. To our knowledge, the association of OM with HLA phenotypes after HSCT has not been specifically investigated to date. We aimed to assess whether an association of HLA phenotype and OM after allogeneic HSCT exists.

\section{Methods}

\subsection{Patients}


We enrolled patients who underwent allogeneic HSCT in our Intensive Chemotherapy and Transplantation Unit in this prospective and observational study. Patients with unrelated donors or those who died before improvement of OM were excluded from the study. The patients were followed up during their hospitalization in terms of mucositis and other routine outcomes by means of a general form and an OM questionnaire which was performed daily.

\subsection{Conditioning regimen}

In general, cyclophosphamide ( $\mathrm{CY} ; 60 \mathrm{mg} / \mathrm{kg} /$ day on two consecutive days) was combined with busulfan $(\mathrm{BU} ; 4 \mathrm{mg} / \mathrm{kg} /$ day on four consecutive days). Among patients with advanced disease status at transplantation etoposide was added to $\mathrm{BU} / \mathrm{CY}$ regimen. Heavily treated or older patients ( $>50$ years) received non-myeloablative conditioning with fludarabine $\left(30 \mathrm{mg} / \mathrm{m}^{2} /\right.$ day for 3 days) combined with cytarabine and idarubicine or melphalan or $\mathrm{CY}$. One patient with severe aplastic anemia received $\mathrm{CY}$ ( $50 \mathrm{mg} / \mathrm{kg} /$ day on four consecutive days) and ATG. Another patient with beta thalassemia major received Pesaro protocol. BEAC or BEAM was chosen for patients with Hodgkin's lymphoma.

\subsection{GVHD prophylaxis}

All patients received cyclosporine (CsP) and short course methotrexate (MTX) except those who received non-myeloablative regimens. MTX was given in a dose of $15 \mathrm{mg} / \mathrm{m}^{2}$ on day $+1,10 \mathrm{mg} / \mathrm{m}^{2}$ on day $+3,+6$, and in some patients at high risk for GVHD also on day + 11. CsP was started the day before transplantation intravenously, $(1.5 \mathrm{mg} / \mathrm{kg}$, two times daily) as soon as the patient could tolerate, it was given orally $(12.5 \mathrm{mg} / \mathrm{kg} /$ day). During the first month, blood CsP levels were maintained at 200$300 \mathrm{ng} / \mathrm{ml}$. In patients receiving non-myeloablative CR, CsP was combined with mycophenolate mofetil (MPM; 15 mg/day).

\subsection{Supportive care and stem-cell source}

Peritransplant infection prophylaxis was the same in all of the patients. Indication for hematopoetic growth factors was only when graft failure developed. For patients with high risk of GVHD or who did not need graft versus disease effect, the chosen stem cell source was bone marrow (BM).

\subsection{Oral mucosal care}

Oral examinations were carried out on two separate occasions. The baseline examination took place before the $\mathrm{CR}$. It was carried out for all patients by the same dentist group who were working in the dental clinic of a university dentistry application and research center when the patient became a transplant candidate. Afterwards, the patients underwent dental treatment if it was needed to reduce the risk of focal infection. Routine oral care regimens included daily tooth brushing with soft-bristled brushes and topical oral rinses with agents such as $0.2 \%$ chlorhexidine or povidone iodine. OM management was with topical application of anesthetic agents and when needed with systemic narcotic analgesics. Secondly, routine oral care regimens were undertaken during conditioning, neutropenic phase until engraftment or the day 21. 
Patients undergoing HSCT are routinely recommended to stop smoking at least 2 months before transplantation in our unit, but real smoking data was not documented.

\subsection{Assessment of $\mathrm{OM}$ and its association with other variables}

Beginning from the day of transplantation, presence and grade (using WHO criteria: 0: no complaints or findings, 1: soreness/erythema, 2: erythema and ulcerations present, but able to eat solids, 3: ulcers present, but requires liquid diet, 4: oral alimentation not possible) of OM was assessed with daily clinical questioning and examination (10). A maximum OM score of lower than 3 was defined as mild $\mathrm{OM}$ and presence of scores equal to or greater than 3 was defined as severe OM. Weighted total mucositis score (WTMS) was calculated as sum of OM grade of each day from the onset until the last day of OM.

Neutrophil engraftment time (NET) was defined as a neutrophil count above $500 / \mathrm{mm}^{3}$ for three consecutive days and platelet engraftment time (PET) was defined as a platelet count above $20000 / \mathrm{mm}^{3}$ for three consecutive days without platelet transfusions. The association of OM duration, maximum OM grade and WTMS with gender, age, HLA phenotypes, underlying diagnosis, CR, stem cell source, engraftment times, and complications were investigated.

\subsection{Statistical Analyses}

We performed statistical analyses using "SPSS version 13 (SPSS Inc. Chicago. Illinois, USA)". Categorical variables are presented with numbers and percentages while continuous variables are presented as means \pm standard deviations or medians (interquartile ranges) where compatible. Fisher's exact and Pearson chi-square tests were used to assess categorical data. Student's t-test was used to compare continuous variables while Mann Whitney $U$ test was used to compare ordinal variables. One way ANOVA test was used in multiple group analyses of numeric data. Parameters of OM of patients with certain HLA phenotypes were compared with the rest of the patients who did not carry those alleles. Pearson and Spearman correlation tests were used in the correlation analyses as required. The strength of correlation coefficient ( $r$ ) was defined as: 0.1 to 0.3 , weak; 0.3 to 0.5 , moderate; and $>0.5$, strong. Ordinal regression analysis was performed to define independent factors associated with higher maximum OM grade. Linear regression analysis was performed to define independent correlates of higher OM duration and WTMS. Factors included in the regression analyses were age, presence of myeloablative regimen, NET, and HLA phenotypes which were significantly associated with OM severity in univariate analyses. Differences were considered significant when $p$ values were $<0.05$.

\section{Results}

We enrolled 45 patients ( 29 males, 16 females). We presented the characteristics of the patients in Table 1. All but two of the transplants were from full matched sibling donors. One of the patients was transferred to intensive care unit while she had grade $4 \mathrm{OM}$, so only maximum $\mathrm{OM}$ grade of this patient was used in the analyses. The most frequent diagnoses were acute lymphoblastic leukemia $(n=15)$, acute myeloid leukemia $(n=11)$, chronic myeloid leukemia $(n=4)$ and multiple myeloma $(n=4)$. The stem cell source was peripheral blood (PB) in 24 (53.3\%) and BM in 21 (46.7\%). 
Table 1

General characteristics of the study population $(n=45)$

\begin{tabular}{|c|c|}
\hline Sex (n, males/females) & 29/16 \\
\hline Age (years, mean \pm SD [range]) & $31.2 \pm 9.9[16-48]$ \\
\hline Full-matched sibling donors $(\mathrm{n}, \%)$ & $43,95.6$ \\
\hline Complete follow-up data for oral mucositis $(\mathrm{n}, \%)$ & $44,97.8$ \\
\hline Neutrophil engraftment occurred $(\mathrm{n}, \%)$ & $42,93.3$ \\
\hline Neutrophil engraftment time (days, mean \pm SD) & $19.9 \pm 4.5$ \\
\hline Platelet engraftment occurred $(n, \%)$ & 38. 82.2 \\
\hline Platelet engraftment time (days, mean \pm SD) & $20 \pm 7.2$ \\
\hline Peripheral blood derived HSCT (n, \%) & 24,53 \\
\hline Bone marrow derived HSCT (n, \%) & 21,47 \\
\hline Myeloablative regimen ( $\mathrm{n}, \%)$ & 36,80 \\
\hline Diseases $(n)$ & 16 \\
\hline Acute lymphoid leukemia & 11 \\
\hline Acute myeloid leukemia & 4 \\
\hline Chronic myeloid leukemia & 4 \\
\hline Multiple myeloma & 2 \\
\hline Chronic lymphoid leukemia & 2 \\
\hline Aplastic anemia & 2 \\
\hline Hodgkin's disease & 1 \\
\hline Non-Hodgkin lymphoma & 1 \\
\hline Thalassemia major & 2 \\
\hline Others & \\
\hline
\end{tabular}

Neutrophil $(22.5 \pm 4$ vs. $17.7 \pm 3.7, p<0.001)$ and platelet $(24 \pm 6.8$ vs. $16.6 \pm 5.6, p=0.001)$ engraftments occurred later in the BM-derived HSCT group compared to PB-derived HSCT group.

The list of HLA alleles are presented in Table 2. 
Table 2

The frequencies of HLA alleles of the study population

\begin{tabular}{|c|c|c|}
\hline HLA-A allele (n, \%) & HLA-B allele $(n, \%)$ & HLA-DR allele $(n, \%)$ \\
\hline A1 $(4,8.9)$ & B7 $(6,13.3)$ & $\mathrm{DR} 1(1,2.2)$ \\
\hline A2 $(22,48.9)$ & B8 $(4,8.9)$ & DR3 $(8,17.8)$ \\
\hline A3 $(16,35.6)$ & B13 $(5,11.1)$ & DR4 $(16,35.6)$ \\
\hline A11 $(4,8.9)$ & $\mathrm{B} 15(2,4.4)$ & DR7 $(7,15.6)$ \\
\hline A23 $(3,6.7)$ & $\mathrm{B} 18(2,4.4)$ & DR8 $(3,6.7)$ \\
\hline A24 $(13,28.9)$ & B27 $(4,8.9)$ & DR10 $(3,6.7)$ \\
\hline A26 $(9,20)$ & B35 $(13,28.9)$ & DR11 $(22,48.9)$ \\
\hline A29 $(1,2.2)$ & B37 $(1,2.2)$ & DR12 $(4,8.9)$ \\
\hline A30 $(4,8.9)$ & B38 $(8,17.8)$ & DR13 $(7,15.6)$ \\
\hline A31 $(2,4.4)$ & B39 $(2,4.4)$ & DR14 $(7,15.6)$ \\
\hline A32 $(2,4.4)$ & B40 $(1,2.2)$ & DR15 $(8,17.8)$ \\
\hline A33 $(3,6.7)$ & B44 $(4,8.9)$ & DR16 $(4,8.9)$ \\
\hline A68 $(6,13.3)$ & B45 $(1,2.2)$ & \\
\hline \multirow[t]{13}{*}{ A69 $(1,2.2)$} & B48 $(1,2.2)$ & \\
\hline & B49 $(5,11.1)$ & \\
\hline & B50 $(4,8.9)$ & \\
\hline & B51 $(12,26.7)$ & \\
\hline & B52 $(3,6.7)$ & \\
\hline & B53 $(1,2.2)$ & \\
\hline & B55 $(2,4.4)$ & \\
\hline & B57 $(2,4.4)$ & \\
\hline & B58 $(2,4.4)$ & \\
\hline & $\mathrm{B} 60(1,2.2)$ & \\
\hline & $\mathrm{B} 62(2,4.4)$ & \\
\hline & $\mathrm{B} 63(1,2.2)$ & \\
\hline & B65 $(1,2.2)$ & \\
\hline
\end{tabular}




\subsection{Association of OM with other factors}

There were strong correlations between OM duration and WTMS $(r=0.89, p<0.001)$; and between maximum OM grade and WTMS $(r=0.78, p<0.001)$. Maximum grade and duration of OM also had strong correlation $(r=0.56, p<0.001)$. Mean OM duration and median WTMS were similar between male and female patients (Table 3). No correlation was found between age and OM duration or WTMS. Mean $\mathrm{OM}$ duration was also similar among underlying diseases (One way Anova test, $F=1.76, p=0.06$ ). $\mathrm{OM}$ duration, maximum OM grade, and WTMS were similar between PB- and BM- derived HSCT. OM duration, maximum OM grade, and WTMS were similar patients with febrile neutropenia and those without febrile neutropenia. Similarly, patients with and without GVHD had similar durations and severities of OM. Myeloablative regimens were associated with significantly longer OM duration ( $15.3 \pm 4.5$ vs. $11.3 \pm 5.7$ days, $p=0.03$ ). However, myeloablative regimens only tended to have higher median WTMS (30 (16) vs. $21(23), p=0.11$ ) and maximum OM grade values (3 (1) vs. $2(2), p=0.11)$, but the differences were not significant. 
Table 3

Association of study variables with $\mathrm{OM}$ duration and severity

\begin{tabular}{|c|c|c|c|c|c|c|c|c|}
\hline & $\begin{array}{l}\text { Severe } \\
\text { OM (\%) }\end{array}$ & p & $\begin{array}{l}\text { MD (days, } \\
\text { mean } \pm \text { SD) }\end{array}$ & p & $\begin{array}{l}\text { WTMS } \\
\text { (median) }\end{array}$ & $p$ & $\begin{array}{l}\text { Max. MG } \\
\text { (median) }\end{array}$ & p \\
\hline Sex & 62.1 & \multirow[t]{3}{*}{0.8} & $13.8 \pm 4.6$ & \multirow[t]{3}{*}{0.23} & 24 & \multirow[t]{3}{*}{0.28} & 3 & \multirow[t]{3}{*}{0.5} \\
\hline $\begin{array}{l}\text { Males }(n= \\
29)\end{array}$ & 68.8 & & $15.7 \pm 5.4$ & & 31 & & 3 & \\
\hline \multicolumn{5}{|l|}{$\begin{array}{l}\text { Females } \\
(n=16)\end{array}$} & & & & \\
\hline HSCT & 62.5 & \multirow[t]{3}{*}{1} & \multirow{3}{*}{$\begin{array}{l}14.2 \pm 5.5 \\
14.9 \pm 4.2\end{array}$} & \multirow[t]{3}{*}{0.7} & 26.5 & \multirow[t]{3}{*}{0.9} & 3 & \multirow[t]{3}{*}{0.6} \\
\hline $\mathrm{PB}(\mathrm{n}=24)$ & 66.7 & & & & 26 & & 3 & \\
\hline $\begin{array}{l}\text { BM }(n= \\
21)\end{array}$ & & & & & & & & \\
\hline $\mathrm{CR}$ & 69.4 & \multirow[t]{3}{*}{0.25} & \multirow{3}{*}{$\begin{array}{l}15.3 \pm 4.5 \\
11.3 \pm 5.7\end{array}$} & \multirow[t]{3}{*}{0.03} & 30 & \multirow[t]{3}{*}{0.11} & 3 & \multirow[t]{3}{*}{0.1} \\
\hline $\begin{array}{l}\text { MA }(n= \\
36)\end{array}$ & 44.4 & & & & 21 & & 2 & \\
\hline \multicolumn{4}{|l|}{$\begin{array}{l}\text { NMA }(n= \\
9)\end{array}$} & & & & & \\
\hline $\mathrm{FN}$ & 60 & \multirow[t]{3}{*}{0.3} & $14.4 \pm 5.4$ & \multirow[t]{3}{*}{0.9} & 25.5 & \multirow[t]{3}{*}{0.7} & 3 & \multirow[t]{3}{*}{0.6} \\
\hline $\begin{array}{l}\text { Present (n } \\
=35)\end{array}$ & 80 & & $14.7 \pm 3$ & & 29 & & 3 & \\
\hline \multicolumn{5}{|l|}{$\begin{array}{l}\text { Absent (n } \\
=10)\end{array}$} & & & & \\
\hline GVHD & 58.3 & \multirow[t]{3}{*}{0.7} & $13.9 \pm 5.5$ & \multirow[t]{3}{*}{0.7} & 25.5 & \multirow[t]{3}{*}{0.97} & 3 & \multirow[t]{3}{*}{0.97} \\
\hline $\begin{array}{l}\text { Present }(\mathrm{n} \\
=12)\end{array}$ & 66.7 & & $14.7 \pm 4.8$ & & 26.6 & & 3 & \\
\hline $\begin{array}{l}\text { Absent ( } \mathrm{n} \\
=33 \text { ) }\end{array}$ & & & & & & & & \\
\hline
\end{tabular}

Duration of OM and WTMS showed positive correlation with NET $(r=0.456, p=0.003$ and $r=0.381, p=$ 0.014 respectively) but not with PET ( $r=0.06$ and $r=0.111$ respectively, $p>0.05$ for both). The correlation of NET and OM duration was strong in patients with BM-derived HSCT $(r=0.727, p=0.001)$ and moderate in patients with PB-derived HSCT $(r=0.397, p=0.06)$. The correlation of NET and WTMS was strong in 
patients with BM-derived HSCT $(r=0.523, p=0.026)$ and moderate in patients with PB-derived HSCT $(r=$ $0.334, p=0.12$ ).

\subsection{Association of HLA phenotypes with OM}

All patients with HLA-B44 phenotype $(n=3)$ developed mild OM (Fisher's exact test, $p=0.039)$ while all patients with HLA-DR15 phenotype $(n=8)$ developed severe OM (Fisher's exact test, $p=0.037)$. HLA-A23, HLA-B44, HLA-DR15, and HLA-DR11 were associated with shorter OM duration and lower WTMS while HLA-A26 and HLA-B52 were associated with longer OM duration and higher WTMS (Table 4).

Table 4

Association of HLA alleles with oral mucositis duration and severity

\begin{tabular}{|c|c|c|c|c|c|c|}
\hline HLA alleles* & $\begin{array}{l}\text { MD (days) } \\
\text { mediant or } \\
\text { mean } \pm \\
\mathrm{SD}^{* \star}\end{array}$ & $Z+/ t^{\star \star}$ & $\mathbf{p}$ & $\begin{array}{l}\text { WTMS } \\
\text { (median) }\end{array}$ & $\mathrm{Zt}$ & $\mathbf{p}$ \\
\hline A23 allele $+(n=3,6.8 \%)$ vs. & $9+$ & $-1.89 \dagger$ & $0.06 t$ & 9 & -1.468 & 0.157 \\
\hline A23 allele $-(n=41,93.2 \%)$ & $16 \dagger$ & & & 26 & & \\
\hline \multirow{2}{*}{$\begin{array}{l}\text { A26 allele }+(n=9,20.45 \%) \\
\text { vs. } \\
\text { A26 allele }-(n=35,79.55 \%)\end{array}$} & $17.6 \pm 3.2^{\star \star}$ & $-2.19 \star \star$ & $0.034 * \star$ & 36 & -2.315 & 0.021 \\
\hline & $13.7 \pm 5^{\star \star}$ & & & 24 & & \\
\hline B44 allele $+(n=3,6.8 \%)$ vs. & $10+$ & $-1.50 \dagger$ & $0.14 \dagger$ & 10 & -1.934 & 0.053 \\
\hline B44 allele - $(n=41,93.2 \%)$ & \multicolumn{2}{|l|}{$15+$} & & \multicolumn{3}{|l|}{27} \\
\hline B52 allele $+(n=3,6.8 \%)$ vs. & $19+$ & $-2.11 \dagger$ & $0.03+$ & 42 & -1.981 & 0.048 \\
\hline B52 allele - $(n=41,93.2 \%)$ & \multicolumn{2}{|l|}{$15+$} & & \multicolumn{3}{|l|}{26} \\
\hline \multirow{2}{*}{$\begin{array}{l}\text { DR11 allele }+(n=18,40.9 \%) \\
\text { vs. } \\
\text { DR11 allele }-(n=26,59.1 \%)\end{array}$} & $13+$ & $-2.60 \dagger$ & $0.009 \dagger$ & 23 & -2.497 & 0.013 \\
\hline & $16.5+$ & & & \multicolumn{3}{|l|}{32.5} \\
\hline & $16+$ & $-0.83 \dagger$ & $0.43+$ & 36.5 & -1.477 & 0.142 \\
\hline $\begin{array}{l}\text { DR15 allele - }(n=36 \\
81.82 \%)\end{array}$ & $15+$ & & & \multicolumn{3}{|l|}{25.5} \\
\hline \multicolumn{7}{|c|}{ MD: Mucositis duration, WTMS: Weighted total mucositis score } \\
\hline \multicolumn{7}{|c|}{ *Frequency and percentages of HLA alleles which are associated with mucositis duration or severity. } \\
\hline \multicolumn{7}{|l|}{ **Student's t test } \\
\hline †Mann Whitney U test & & & & & & \\
\hline
\end{tabular}




\subsection{Regression Analyses}

Ordinal regression analysis revealed independent correlates of higher maximum OM grade as HLA-B44 ( $p$ $=0.03$, Wald: $4.7,95 \% \mathrm{Cl} 0.36-7.2$ ) and HLA-A23 ( $p=0.049$, Wald: 3.9, 95\% Cl 0.009-6.4). Linear regression analysis revealed independent correlates of higher OM duration and WTMS as HLA-B44 $(p=$ $0.024, \mathrm{t}:-2,3,95 \% \mathrm{Cl}:[-13.2]-[-1]$ and $\mathrm{p}=0.035, \mathrm{t}:-2.2,95 \% \mathrm{Cl}:[-39]-[-1.5]$, respectively) and HLA-DR11 $(p=0.03, t:-2.2,95 \% \mathrm{Cl}:[-5.8]-[-0.3]$ and $p=0.025, \mathrm{t}-2.3, \mathrm{Cl}:[-18]-[-1.3]$, respectively). NET was also independently correlated with OM duration ( $p=0.01, \mathrm{t}: 2.8,95 \% \mathrm{Cl}: 0.1-0.72)$, but not with WTMS. HLAA23 tended to be independently correlated with OM duration ( $p=0.053$, t: $-2,95 \% \mathrm{Cl}$ : $[-10.4]-0.1)$ but not with WTMS.

\subsection{Association of HLA phenotypes with other factors}

Neutrophil engraftment duration was longer in patients with HLA-A2 phenotype ( $n=18,21.6 \pm 4$ vs. $18.6 \pm$ 4.5 days, $p=0.035)$ while it was shorter in patients with HLA-A24 $(n=10,16.9 \pm 4.3$ vs. $20.8 \pm 4.2$ days, $p$ $=0.014)$. Platelet engraftment duration was longer in patients with HLA-DR8 $(n=3,28.3 \pm 8.7$ vs. $19.2 \pm$ 6.7 days, $p=0.033$ ) phenotype. No association between HLA phenotypes and development of febrile neutropenia was found. Frequency of GVHD was increased in patients with HLA-B8 ( $n=4,75 \%$ vs. $22 \%$, Fisher's exact test, $\mathrm{p}=0.05$ ) phenotype.

\section{Discussion}

Although any site of the alimentary tract may be affected from the adverse effects, OM has drawn most of the interest in this topic. It is well known that $\mathrm{OM}$ is associated with significant morbidity and may have a role in increased mortality (1). However, evidence-based treatment options for OM are limited, thus primary prevention is more important $(1,11)$. Prediction of duration and severity of $\mathrm{OM}$ and determination of important risk factors in every patient may facilitate providing of individualized preventive precautions and management for OM. Although certain parameters have been suggested as risk factors for mucositis, including poor oral health, low body mass index, extremes of age, and female sex, none has been consistent or accurate (12).

While recent data underscore the importance of certain genetic factors in the pathogenesis of OM (12), the association of HLA phenotype and OM has drawn little attention. To the best of our knowledge, only one recent study reported that low levels of HLA-DRB1 and HLA-DRB5 expression were associated with a more severe $\mathrm{OM}$ in patients with multiple myeloma who underwent high-dose melphalan treatment (13). The authors concluded that expression levels of HLA-DRB1 and HLA-DRB5 may serve as potential predictive biomarkers for mucositis severity. Thus, we aimed to evaluate the association of HLA phenotype and OM risk in patients undergoing allogeneic HSCT.

Inflammatory bowel diseases are chronic immunologically mediated diseases of the gut mucosa. Some clinical features of Crohn's disease and ulcerative colitis may be influenced by specific HLA-DR alleles. 
Behçet's disease is a chronic multisystem inflammatory disorder characterized mainly by recurrent oral ulcers, ocular involvement, genital ulcers, and skin lesions, presenting with remissions and exacerbations. It is thought that both environmental and genetic factors contribute to its onset and development. Apart of positive association with HLA-B*51, additional independent associations with $H L A-B * 15,-B * 27,-B \star 57$, and $-A \star 26$ have been shown as risk factors for Behçet's disease, while HLA-B*49 and $-A * 03$ may be protective from Behçet's disease (14). In IBDs and Behçet's disease mucositis is a manifestation of the disease and it responds to immunosuppressive therapy. Contrarily, OM develops in association with immunosuppressive therapy in patients undergoing HSCT. Although the pathogenesis of mucositis may be different in inflammatory disease and after HSCT, it may be speculated that development of mucosal inflammation in HSCT may also have an association with certain HLA phenotypes. Our study suggested some possible associations between HLA phenotypes and duration and severity of OM. In patients having HLA alleles A23, B44, DR15, and DR11, OM was milder and OM duration was shorter. In contrast, in patients with HLA alleles $A 26$ and B52, OM was more severe and OM duration was longer. Regression analysis suggests that HLA-B44, HLA-DR11, and HLA-A23 may be independently associated with milder $\mathrm{OM}$.

Data regarding influence of age and gender on the $\mathrm{OM}$ development is conflicting $(3,5,15,16)$. Our study population was in general young and the age range was relatively narrow. Thus it is not possible to make clear conclusions about the age effect on OM risk. We did not found any association of OM and sex.

The CR in our study was primarily myeloablative, which was associated with a significantly longer OM duration and a non-significant increase in the severity of $\mathrm{OM}$. Therefore, $\mathrm{CR}$ could be a confounding factor in our study. Most of HSCT indications were acute leukemia (57.7\%). So it is not possible to make an interpretation about the risk of $\mathrm{OM}$ and underlying diagnosis.

Frequency of febrile neutopenia was similar in patients with mild or severe OM. Duration and severity of OM did not show any correlation with GVHD. There are studies having similar results with our study (1719) whereas there are also studies showing correlation (18-20).

$\mathrm{OM}$ duration and severity correlated with neutrophil engraftment. This finding is in accordance with the fact that neutrophil quantity and quality may be important in mucosal defense and recovery. Our findings regarding association of myeloablative regimen and prolonged neutropenia with longer duration of $\mathrm{OM}$ were consistent with previous reports $(1,3-5,21)$.

Source of HSCT (PB or BM) was not found associated with OM duration or severity. Although neutrophil engraftment occurred earlier in patients with PB-derived HSCT, OM duration was not shorter. This finding indicates that solely earlier recovery from neutropenia may not result in a better course of OM and other factors also influence the course of OM. Some studies suggest more severe OM after BM-derived HSCT compared to PB-derived HSCT (22). However, in this study, NET was significantly faster in the PB-derived HSCT group which may account for the difference between the rates of severe OM in both groups. 
To our knowledge, WTMS was not used previously in the literature and provided some important information in our study. Utilization of WTMS in more detailed and larger studies are needed to assess its validity and importance better.

The limitations of our study were the small sample size which might result in underestimation of some potentially important risk factors for $\mathrm{OM}$. The lack of reference studies in the literature also shadows our findings' importance. It is not possible to reach strict conclusions about the association between mucositis and HLA alleles and there is need for larger scale studies in which more homogenous patients and treatment modalities are investigated. In this regard, the small numbers of patients in HLA allele groups may be associated with type II error. We could not determine the effect of MTX on OM or HLA alleles because all but one patient received MTX treatment for GVHD prophylaxis. We think that dental hygiene was not a significant confounder in our study because all patients had dental health management by the same dentist team. However, we did not check if the patients complied with oral selfcare measures and this may still be a confounding factor.

All patients were recommended to cease smoking two months before HSCT. However we do not have data about smoking status of the study population. Thus, we could not assess the influence of smoking on OM in our study.

Furthermore, influence of individual pain threshold, concomitant infections and experience of the observer on assessment of OM grade and lack of features like xerostomia, tastelessness and dysphagia in the WHO scale may have affected accurate assessment of OM. Thus it is hard to make further interpretations.

\section{Conclusions}

In conclusion, we identified that some HLA alleles correlated with OM severity and duration. These findings may facilitate in prediction of injury risk and possible associated morbidity and may provide incorporation of individualized preventive and treatment approaches. Patients with such HLA phenotypes may need more aggressive oral health care and/or less severe CR. This finding needs to be confirmed in larger and more detailed studies with other genetic susceptibility assessments.

\section{Declarations}

\section{Ethics approval and consent to participate}

The study was conducted in accordance with the Helsinki Declaration of 1975 (as revised in 1983) and was approved by the local ethical committee. All the patients provided written informed consent.

\section{Consent for publication}

Not applicable. 
Availability of data and materials

We agree that the materials described in the manuscript, including all relevant raw data, will be freely available to any scientist wishing to use them for non-commercial purposes, without breaching participant confidentiality.

\section{Competing interests}

The authors declare that there are no conflicts of interest.

\section{Funding}

The authors have nothing to disclose.

\section{Authors' contributions}

All authors contributed to the design and performance of this study and in writing and critical revision of the final manuscript.

\section{Acknowledgements}

We thank David Chapman for English editing in the document.

\section{References}

1. Scully C, Sonis S, Diz PD. Oral mucositis. Oral diseases. 2006;12(3):229-41.

2. Woo SB, Sonis ST, Monopoli MM, Sonis AL. A longitudinal study of oral ulcerative mucositis in bone marrow transplant recipients. Cancer. 1993;72(5):1612-7.

3. Barasch A, Peterson DE. Risk factors for ulcerative oral mucositis in cancer patients: unanswered questions. Oral oncology. 2003;39(2):91-100.

4. Kashiwazaki H, Matsushita T, Sugita J, Shigematsu A, Kasashi K, Yamazaki Y, et al. A comparison of oral mucositis in allogeneic hematopoietic stem cell transplantation between conventional and reduced-intensity regimens. Support Care Cancer. 2012;20(5):933-9.

5. Vagliano L, Feraut C, Gobetto G, Trunfio A, Errico A, Campani V, et al. Incidence and severity of oral mucositis in patients undergoing haematopoietic SCT-results of a multicentre study. Bone Marrow Transplant. 2011;46(5):727-32.

6. Sheldon S, Poulton K. HLA typing and its influence on organ transplantation. Methods in molecular biology. 2006;333:157-74.

7. Lehner T, Welsh KI, Batchelor JR. The relationship of HLA-B and DR phenotypes to Behcet's syndrome, recurrent oral ulceration and the class of immune complexes. Immunology. 1982;47(4):581-7. 
8. Jores RD, Frau F, Cucca F, Grazia Clemente M, Orru S, Rais M, et al. HLA-DQB1*0201 homozygosis predisposes to severe intestinal damage in celiac disease. Scandinavian journal of gastroenterology. 2007;42(1):48-53.

9. Turkcapar N, Toruner M, Soykan I, Aydintug OT, Cetinkaya H, Duzgun N, et al. The prevalence of extraintestinal manifestations and HLA association in patients with inflammatory bowel disease. Rheumatology international. 2006;26(7):663-8.

10. Sonis ST, Elting LS, Keefe D, Peterson DE, Schubert M, Hauer-Jensen M, et al. Perspectives on cancer therapy-induced mucosal injury: pathogenesis, measurement, epidemiology, and consequences for patients. Cancer. 2004;100(9 Suppl):1995-2025.

11. Petti S, Polimeni A, Berloco PB, Scully C. Orofacial diseases in solid organ and hematopoietic stem cell transplant recipients. Oral Dis. 2013;19(1):18-36.

12. Cinausero M, Aprile G, Ermacora P, Basile D, Vitale MG, Fanotto V, et al. New Frontiers in the Pathobiology and Treatment of Cancer Regimen-Related Mucosal Injury. Front Pharmacol. 2017;8.

13. Marcussen M, Bodker JS, Christensen HS, Johansen P, Nielsen S, Christiansen I, et al. Molecular Characteristics of High-Dose Melphalan Associated Oral Mucositis in Patients with Multiple Myeloma: A Gene Expression Study on Human Mucosa. PLoS One. 2017;12(1):e0169286.

14. Takeuchi M, Kastner DL, Remmers EF. The immunogenetics of Behcet's disease: A comprehensive review. J Autoimmun. 2015;64:137-48.

15. Zalcberg J, Kerr D, Seymour L, Palmer M. Haematological and non-haematological toxicity after 5fluorouracil and leucovorin in patients with advanced colorectal cancer is significantly associated with gender, increasing age and cycle number. Tomudex International Study Group. Eur J Cancer. 1998;34(12):1871-5.

16. McCarthy GM, Awde JD, Ghandi H, Vincent M, Kocha WI. Risk factors associated with mucositis in cancer patients receiving 5-fluorouracil. Oral Oncol. 1998;34(6):484-90.

17. Vokurka S, Steinerova K, Karas M, Koza V. Characteristics and risk factors of oral mucositis after allogeneic stem cell transplantation with FLU/MEL conditioning regimen in context with BU/CY2. Bone Marrow Transplant. 2009;44(9):601-5.

18. Sugita J, Matsushita T, Kashiwazaki H, Kosugi M, Takahashi S, Wakasa K, et al. Efficacy of folinic acid in preventing oral mucositis in allogeneic hematopoietic stem cell transplant patients receiving MTX as prophylaxis for GVHD. Bone Marrow Transplant. 2012;47(2):258-64.

19. Perkins J, Field T, Kim J, Kharfan-Dabaja MA, Fernandez H, Ayala E, et al. A randomized phase II trial comparing tacrolimus and mycophenolate mofetil to tacrolimus and methotrexate for acute graftversus-host disease prophylaxis. Biol Blood Marrow Transplant. 2010;16(7):937-47.

20. Vokurka S, Svoboda T, Jungova A, Karas M, Koza V. Oral cryotherapy can significantly reduce oral mucositis but not acute GVHD incidence in Flu/Mel conditioning allo-SCT. Bone Marrow Transplant. 2012;47(5):739-41.

21. Busemann C, Wilfert H, Neumann T, Kiefer T, Dölken G, Krüger WH. Mucositis after reduced intensity conditioning and allogeneic stem cell transplantation. Onkologie. 2011;34(10):518-24. 
22. Stamatović D, Balint B, Tukić L, Elez M, Tarabar O, Todorović M, et al. Impact of stem cell source on allogeneic stem cell transplantation outcome in hematological malignancies. Vojnosanit Pregl. 2011;68(12):1026-32. 